\title{
Bilateral Blunt Internal Carotid Artery Occlusions Associated with Multiple Trauma: A Case Report
}

\author{
Ayumu Yamaoka, Kei Miyata, Naofumi Bunya, Eichi Narimatsu \\ Department of Emergency Medicine, Sapporo Medical University, Sapporo, Japan \\ Email:yamaoka@sapmed.ac.jp
}

How to cite this paper: Yamaoka, A., Miyata, K., Bunya, N. and Narimatsu, E. (2017) Bilateral Blunt Internal Carotid Artery Occlusions Associated with Multiple Trauma: A Case Report. Open Journal of Modern Neurosurgery, 7, 49-54. https://doi.org/10.4236/ojmn.2017.73006

Received: April 16, 2017

Accepted: June 25, 2017

Published: June 28, 2017

Copyright (c) 2017 by authors and Scientific Research Publishing Inc. This work is licensed under the Creative Commons Attribution International License (CC BY 4.0).

http://creativecommons.org/licenses/by/4.0/

\begin{abstract}
In multiple trauma, blunt carotid artery injuries (BCAIs) have occasionally been reported. However, bilateral blunt carotid artery occlusions (Grade 4 BCAIs) associated with multiple trauma are rare, and delays in diagnosis and treatment result in a lethal outcome. Here, we report our experience with bilateral carotid artery occlusions. A 76-year-old female suffered multiple traumas in a motor vehicle accident. On arrival at our hospital, she presented in a coma, with left mydriasis and unreactive pupils. Computed tomography (CT) showed bifrontal intracranial epidural hematoma and fractures of the facial bone and anterior skull base, and osteoplastic craniotomy was urgently undertaken for the epidural hematoma. However, the comatose state and unreactive pupils persisted during the post-operative course. Serial head CT findings showed progressive bilateral ischemic changes, and radiological examinations revealed bilateral internal carotid artery occlusions. We speculated that bilateral Grade 4 BCAIs had induced progressive cerebral infarctions. The patient partially responded to anticoagulation therapy with heparin infusion, but died of multiple organ failure on day 15 . When bilateral progressive ischemic changes are observed in a patient with severe traumatic brain injury, bilateral Grade 4 BCAIs should be considered in the differential diagnosis. CT angiography as part of whole-body $\mathrm{CT}$ at admission may be effective for preventing delays in diagnosis and treatment of bilateral Grade 4 BCAIs.
\end{abstract}

\section{Keywords}

Bilateral Blunt Carotid Artery Occlusions, Progressive Bilateral Cerebral Infarctions, Whole-Body Computed Tomography

\section{Introduction}

In previous reports, blunt cerebrovascular injuries have occurred in $0.18 \%$ to 
$2.70 \%$ of blunt-trauma patients [1], and approximately half of these have been diagnosed as carotid artery injuries. These arterial injuries can lead to abnormal narrowing or occlusion, as well as pseudoaneurysm. The Denver grading scale for blunt carotid artery injury (BCAI) has been correlated with infarction rates (Grade 1: 3.2\%, Grade 2: 9.1\%, Grade 3: 9.3\%, and Grade 4: 58.3\%) [2]. Advances in diagnostic and treatment algorithms based on this scale have contributed to early treatment and improved outcomes [3]. However, blunt injuries with complete occlusion of the carotid artery (Grade 4 BCAI) are associated with high mortality and poor neurologic outcome [4]. Mild or moderate bilateral BCAIs have occasionally been reported [5] [6]. Although there are several reports on bilateral Grade 4 BCAIs caused by hanging [7], very few reports in multiple traumas are available. Here, we report our experience with bilateral Grade 4 BCAIs that had resulted in bilateral progressive cerebral infarction, and review published work.

\section{Case Report}

A 76-year-old female pedestrian was involved in a motor vehicle accident. On arrival at our hospital, she was unconscious with a Glasgow Coma Scale of 3, and presented with head trauma with left mydriasis and unreactive pupils. Her vital signs were respiratory rate 22 breaths/min, blood pressure 186/140 $\mathrm{mmHg}$, and heart rate $104 \mathrm{bpm}$. Her oxygen saturation on pulse oximetry $\left(\mathrm{SpO}_{2}\right)$ was $100 \%$ using $10 \mathrm{~L} / \mathrm{min} \mathrm{O}_{2}$. Whole-body computed tomography (WBCT) showed bifrontal epidural hematoma (Figure 1(a)), brain contusion, subarachnoid hemorrhage, skull fracture from the bifrontal to the left temporal region (Figure 1(b)), left anterior clinoid process fracture, C3 vertebral-body fracture, bilateral
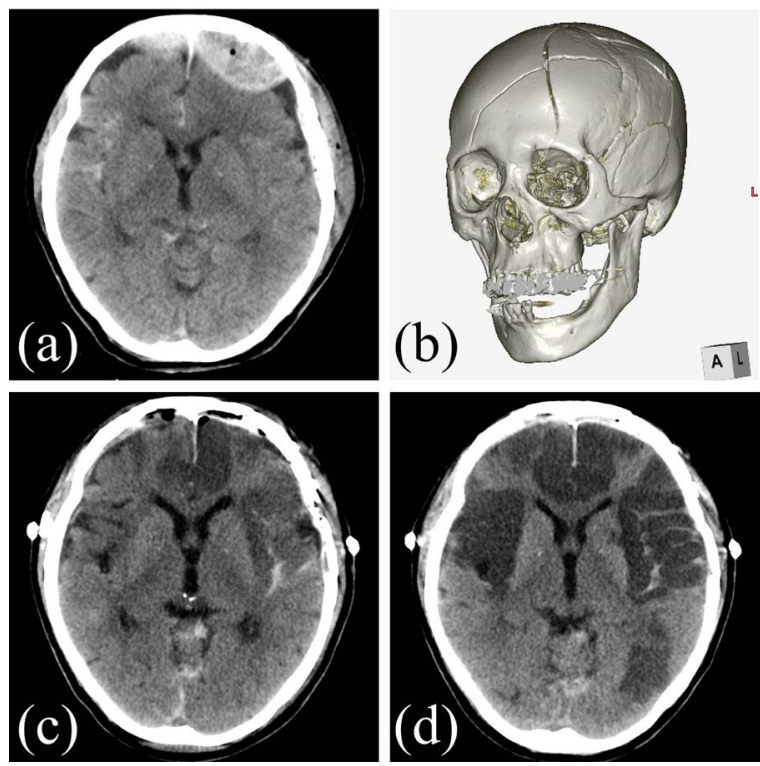

Figure 1. Computed tomography (CT) images of the head at admission ((a), (b)) showed acute epidural hematoma, traumatic subarachnoid hemorrhage, and skull fracture from the bifrontal to the left temporal region. Head CT on days 4 and 7 ((c), (d)) showed progressive ischemic changes from dominant on the left hemisphere to symmetrical. 
pubis-ischium fractures, and left tibial-fibular fracture. Osteoplastic craniotomy was urgently undertaken for the epidural hematoma. The lacerated superior sagittal sinus, which caused massive bleeding, was sutured with 6-0 monofilament. Intracranial pressure (ICP) management was performed in the intensive care unit (ICU), and included administration of an osmotic diuretic and sedative analgesic. On day 3 , magnetic resonance imaging (MRI) of the head and cervical spinal cord were performed for further evaluation of the prolonged deep coma and unreactive pupils. Diffusion-weighted imaging of the head showed cortical laminar hyperintensities in the bifrontal lobes (Figure 2(a) and Figure 2(b)), cerebellum, and brainstem. On day 4, ICP was elevated above $30 \mathrm{mmHg}$. On head CT, the bilateral frontal and temporal lobe and left insular cortex were affected (Figure 1(c)). The lesions showed progressive and symmetrical worsening on day 7 (Figure 1(d)). CT angiography (CTA) of the head and neck showed disappearance of the bilateral middle cerebral arteries. The left internal carotid artery (ICA) disappeared just distal to the carotid bifurcation, and the right ICA distal to the carotid siphon (Figure 3(a) and Figure 3(b)). Sonographic examination of the left carotid bifurcation demonstrated false lumen thrombosis and slightly antegrade blood flow in the narrow true lumen (Figure $3(\mathrm{c})$ ). We retrospectively recognized bilateral BCAIs (left side: Grade 4, right side: Grade 2) on head and cervical MRI performed on day 3. T1-weighted fast field echo imaging had shown signal loss of the left ICA (Figure 2(c)). T2-weighted imaging just distal to the carotid bifurcation had revealed double lumen sign of the right ICA and thrombotic occlusion of the left ICA (Figure 2(d)). Taking into account the clinical course, we speculated that bilateral Grade 4 BCAIs had caused progressive cerebral infarctions. Anticoagulation therapy with heparin was subsequently started, and expansion of the cerebral infarct region could be prevented. However, multiple organ failure gradually worsened with no neurological improvement. The patient died on day 15.

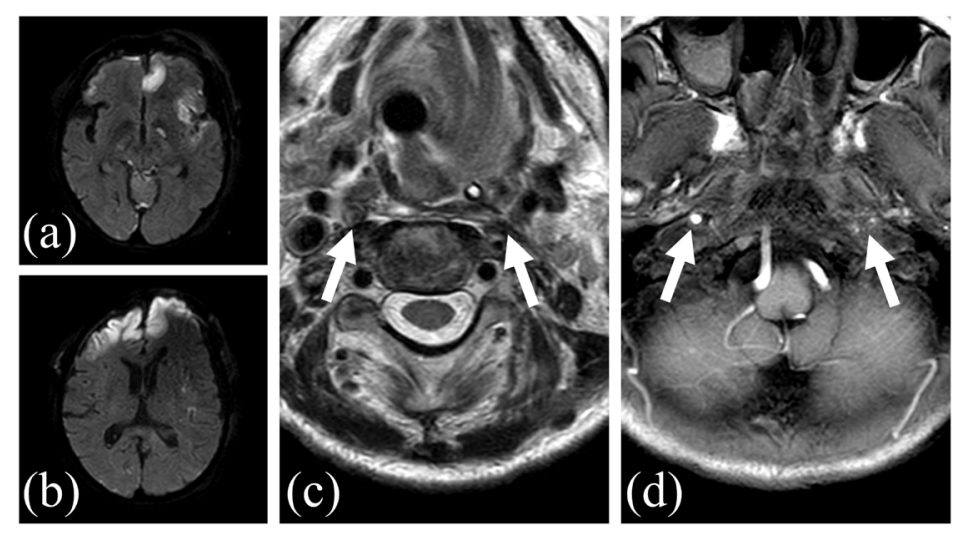

Figure 2. Magnetic resonance imaging (MRI) of the head ((a), (b)) showed multiple hyperintensities in the bifrontal lobes, which limited on cortical laminar. T1-weighted fast field echo imaging of the head (c) showed signal loss of the left internal carotid artery (ICA; white arrow). T2-weighted imaging of the neck just distal to the carotid bifurcation (d) revealed dissection of the right ICA (double lumen sign) and thrombotic occlusion of the left ICA (white arrow). 


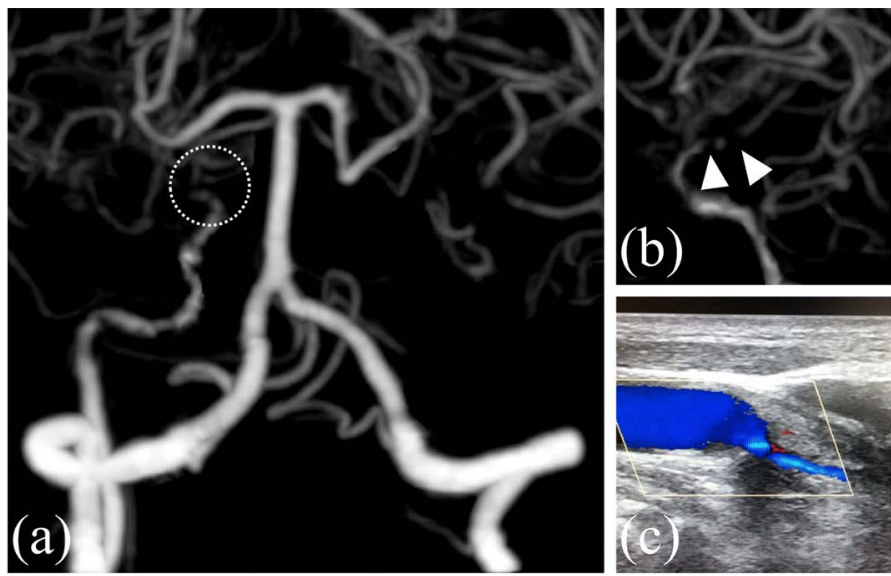

Figure 3. CT angiography (CTA) of cerebral vessels (a) showed poor description of the bilateral middle cerebral arteries and ICAs (white dotted circle). The image of the right ICA (b) showed occlusion on the siphon part (white triangular arrow). Ultrasonic examination of the left ICA (c) showed that the antegrade blood flow of the true lumen had disappeared due to the thrombosis of the false lumen.

\section{Discussion}

\subsection{Pathology of Bilateral Grade 4 BCAIs}

Bilateral Grade 4 BCAIs may occur in multiple trauma in rare cases, and radiographic findings may show progressive and symmetric ischemic changes. We searched the electronic PubMed database and retrieved 38 cases of urgent bilateral BCAIs from the past 20 years. Among these cases, five cases including this case involved bilateral Grade 4 BCAIs [7] [8] [9] [10]. In 3 cases, the patients were injured by direct external forces from hanging [7] [8] [9], and by multiple trauma in the other 2 cases [10]. Mechanisms of BCAI have been reported to involve overstretching caused by hyperextension and rotation of the neck, compression from sudden hyperflexion of the neck, or injuries caused by the cranial base bone [10]. We speculated that the bilateral injuries in our case might have occurred correspondingly.

Early evaluation of the head and neck vessels and appropriate treatment must be fundamental for bilateral Grade 4 BCAIs. For early diagnosis and treatment of BCAI, aggressive screening of the head and neck vessels based on signs or symptoms and risk factors has been suggested [11] [12]. However, we did not perform early evaluation of the head and neck vessels. In some cases, angiography of the head and neck vessels might be performed based on new neurological defects, such as deterioration of consciousness level or appearance of hemiplegia after hospitalization. In our particular case, new neurological defects could not be determined due to the patient's comatose state and severe traumatic brain injury at admission, and we had difficulties diagnosing the bilateral BCAIs based on physical examinations. The bilateral progressive ischemic changes were thought to result from venous sinus obstruction or acute cerebral vasospasm in the initial differential diagnosis. Ultimately, bilateral Grade 4 BCAIs were definitively diagnosed based on head and neck CTA and ultrasonography of the neck. 


\subsection{Early Screening and Treatment for Bilateral Grade 4 BCAIs}

Evaluation and treatment for head and neck vascular injuries should commence as soon as possible. More aggressive screening of the head and neck vessels, regardless of the presence or absence of clinical findings, might be needed. Performing WBCT at admission has been reported to significantly increase survival probability in patients with multiple blunt trauma [13]. Some reports suggest incorporating evaluation of the head and neck vessels into WBCT [14]. In these reports, the arterial phase of WBCT was performed from the face to the pelvis. It has also been reported that in $30 \%$ of blunt cerebrovascular injuries diagnosed with CTA as part of WBCT, the patients did not have the established risk factors for BCAI [15]. Therefore, it is our belief that CTA as part of WBCT at admission is effective for early diagnosis and treatment of bilateral BCAIs.

Early antithrombotic therapy has been recommended for the treatment of BCAI. However, in patients with coagulopathy or severe intracranial hematoma due to blunt multiple trauma, medical therapy might be contraindicated. In accessible Grade 4 BCAI, surgical repair has been considered [11] [12]. However, because there have been few reports on the surgical treatment of bilateral BCAIs associated with multiple trauma, the efficacy and indications have been unclear. Some reports have indicated the efficacy of endovascular therapy for bilateral BCAIs [5] [6] and unilateral Grade 4 BCAI [16] in the acute phase. Thus, we might also take into consideration the indications for carotid artery stenting in patients with bilateral Grade 4 BCAIs with multiple trauma. Further study and long-term follow-up data will be required in future clinical experiences.

\section{Conclusion}

We reported on a case of traumatic bilateral carotid artery occlusions with progressive ischemic changes. Bilateral Grade 4 BCAIs should be considered as a differential diagnosis in patients exhibiting progressive ischemic changes. Early evaluation of the head and neck vessels using CTA as part of WBCT at admission may allow early diagnosis and treatment of BCAI. Early treatment of bilateral Grade 4 BCAIs before a complete stroke occurs is needed for survival and prevention of stroke expansion.

\section{References}

[1] Franz, R.W., Willette, P.A., Wood, M.J., Wright, M.L. and Hartman, J.F. (2012) A Systematic Review and Meta-Analysis of Diagnostic Screening Criteria for Blunt Cerebrovascular Injuries. Journal of the American College of Surgeons, 214, 313327. https://doi.org/10.1016/j.jamcollsurg.2011.11.012

[2] Stein, D.M., Boswell, S., Sliker, C.W., Lui, F.Y. and Scalea, T.M. (2009) Blunt Cerebrovascular Injuries: Does Treatment Always Matter? Journal of Trauma-Injury Infection \& Critical Care, 66, 132-143. https://doi.org/10.1097/TA.0b013e318142d146

[3] Shahan, C.P., Croce, M.A., Fabian, T.C. and Magnotti, L.J. (2017) Impact of Continuous Evaluation of Technology and Therapy: 30 Years of Research Reduces Stroke and Mortality from Blunt Cerebrovascular Injury. Journal of the American College 
of Surgeons, 224, 595-599. https://doi.org/10.1016/j.jamcollsurg.2016.12.008

[4] Cogbill, T.H., Moore, E.E., Meissner, M., Fischer, R.P., Hoyt, D.B., Morris, J.A., et al. (1994) The Spectrum of Blunt Injury to the Carotid Artery: A Multicenter Perspective. Journal of Trauma-Injury Infection \& Critical Care, 37, 473-479. https://doi.org/10.1097/00005373-199409000-00024

[5] Pagnotta, P., Briguori, C., Saluzzo, C.M. and Presbitero, P. (2009) Endovascular Treatment of Traumatic Bilateral Internal Carotid Artery Dissection. The Journal of Invasive Cardiology, 21, E6-E8.

[6] Testerman, G.M. (2010) Bilateral Carotid Stenting after a Motor Vehicle Crash. Southern Medical Journal, 103, 253-255. https://doi.org/10.1097/SMJ.0b013e3181c98ca5

[7] Aspalter, M., Linni, K., Domenig, C.M., Mader, N., Klupp, N. and Holzenbein, T.J. (2013) Successful Repair of Bilateral Common Carotid Artery Dissections from Hanging. Annals of Vascular Surgery, 27, 1186.e7-1186.e15. https://doi.org/10.1016/j.avsg.2013.03.008

[8] Maier, W., Fradis, M., Malatskey, S. and Krebs, A. (1999) Diagnostic and Therapeutic Management of Bilateral Carotid Artery Occlusion Caused by Near-Suicidal Hanging. Annals of Otology, Rhinology \& Laryngology, 108, 189-192. https://doi.org/10.1177/000348949910800215

[9] Kiani, S.H. and Simes, D.C. (2000) Delayed Bilateral Internal Carotid Artery Thrombosis Following Accidental Strangulation. British Journal of Anaesthesia, 84, 521524. https://doi.org/10.1093/oxfordjournals.bja.a013484

[10] Gouny, P., Nowak, C., Smarrito, S., Fadel, E., Hocquet-Cheynel, C. and Nussaume, O. (1998) Bilateral Thrombosis of the Internal Carotid Arteries after a Closed Trauma. Advantages of Magnetic Resonance Imaging and Review of the Literature. The Journal of Cardiovascular Surgery (Torino), 39, 417-424.

[11] Biffl, W.L., Cothren, C.C., Moore, E.E., Kozar, R., Cocanour, C., Davis, J.W., et al. (2009) Western Trauma Association Critical Decisions in Trauma: Screening for and Treatment of Blunt Cerebrovascular Injuries. Journal of Trauma-Injury Infection \& Critical Care, 67, 1150-1153. https://doi.org/10.1097/TA.0b013e3181c1c1d6

[12] Bromberg, W.J., Collier, B.C., Diebel, L.N., Dwyer, K.M., Holevar, M.R., Jacobs, D.G., et al. (2010) Blunt Cerebrovascular Injury Practice Management Guidelines: The Eastern Association for the Surgery of Trauma. Journal of Trauma-Injury Infection \& Critical Care, 68, 471-477.

[13] Huber-Wagner, S., Lefering, R., Qvick, L.M., Körner, M., Kay, M.V., Pfeifer, K.J., et al. (2009) Effect of Whole-Body CT during Trauma Resuscitation on Survival: A Retrospective, Multicentre Study. The Lancet, 373, 1455-1461. https://doi.org/10.1016/S0140-6736(09)60232-4

[14] Laser, A., Kufera, J.A., Bruns, B.R., Sliker, C.W., Tesoriero, R.B., Scalea, T.M., et al. (2015) Initial Screening Test for Blunt Cerebrovascular Injury: Validity Assessment of Whole-Body Computed Tomography. Surgery, 158, 627-635. https://doi.org/10.1016/j.surg.2015.03.063

[15] Bruns, B.R., Tesoriero, R., Kufera, J., Sliker, C., Laser, A., Scalea, T.M., et al. (2014) Blunt Cerebrovascular Injury Screening Guidelines: What Are We Willing to Miss? Journal of Trauma-Injury Infection \& Critical Care, 76, 691-695. https://doi.org/10.1097/TA.0b013e3182ab1b4d

[16] Lauerman, M.H., Feeney, T., Sliker, C.W., Saksobhavivat, N., Bruns, B.R., Laser, A., et al. (2015) Lethal Now or Lethal Later: The Natural History of Grade 4 Blunt Cerebrovascular Injury. Journal of Trauma-Injury Infection \& Critical Care, 78, 1071-1074. https://doi.org/10.1097/TA.0000000000000654 
Submit or recommend next manuscript to SCIRP and we will provide best service for you:

Accepting pre-submission inquiries through Email, Facebook, LinkedIn, Twitter, etc. A wide selection of journals (inclusive of 9 subjects, more than 200 journals)

Providing 24-hour high-quality service

User-friendly online submission system

Fair and swift peer-review system

Efficient typesetting and proofreading procedure

Display of the result of downloads and visits, as well as the number of cited articles Maximum dissemination of your research work

Submit your manuscript at: http://papersubmission.scirp.org/

Or contact ojmn@scirp.org 